\title{
ANÁLISE DE MODELOS E PRÁTICAS DE MEDIÇÃO DE DESEMPENHO DE VALOR AGREGADO: O CASO DE GESTÃO DE PROJETOS DE OBRAS CIVIS PÚBLICAS NO BRASIL
}

\author{
Joaquim TEIXEIRA NETTO ${ }^{1}$ \\ Osvaldo Luiz Gonçalves QUELHAS ${ }^{2}$ \\ ${ }^{1}$ Mestrado Engenharia Civil - Área de Gestão, Universidade Federal Fluminense, joaquimtnetto@gmail.com \\ ${ }^{2}$ Sub-coordenador do curso de Mestrado Profissional em Sistemas de Gestão da Escola de Engenharia, Universidade \\ Federal Fluminense.
}

Recebido em: 15/05/2014 - Aprovado em: 30/06/2014 - Disponibilizado em: 30/07/2014

RESUMO: O controle de desempenho através de indicadores é um instrumento de gestão de grande importância para as empresas. O indicador de valor agregado tem sido utilizado como ferramenta de gestão em diversos tipos de projetos.O presente artigo tem como objetivo comparar a prática do mercado com a teoria de EVM - Earned Value Management (gerenciamento de valor agregado) na gestão de projetos de obras civis públicas no Brasil. O objetivo do artigo é de confrontar a fundamentação teórica do indicador de valor agregado com a prática do mercado.A pesquisa realizada caracterizou-se como aplicada ou tecnológica, foram realizadas revisão de literatura e pesquisa de campo em 03 obras de projetos de obras civis públicas. Nessas obras, foi utilizado o indicador de valor agregado para monitorar o desempenho. A comparação entre a prática do mercado e a teoria de valor agregado foi realizada e foram encontradas diferenças nos processos de obtenção do valor agregado. Foram encontradas diferenças, primordialmente, nos processos de aplicação do EVM. A conclusão final aponta a deficiência nas empresas de maturidade na gestão de projetos.

Palavras-chave: gestão de resultados na construção civil pública;indicador de valor agregado; EVM; maturidade em gestão de projetos.

\begin{abstract}
The control of performance through indicators is a very important management tool for companies .The EVM (Earned Value Management) indicator has been used as a management tool in various types of projects. The main objective of this paper is to compare the practice in the market to the theory of EVM in civil public construction projects in Brazil. The objective of this article is to confront the theoretical basis for the indicator value with market practice. The research was characterized as applied or technological, literature review and field research on 03 in civil public construction projects were carried out. In these projects, the EVM indicator was used for performance monitoring. The comparison between the theory and practice of market on EVM was performed and differences were found in the process of obtaining EVM. Differences were found primarily in the process of implementing EVM. The final conclusion points out the deficiency in mature companies in project management.
\end{abstract}

Keywords: performance management in civil construction; earned value indicator, EVM, project management maturity.

\section{Introdução}

A medição de desempenho através do uso de indicadores tem despertado grande interesse na área de gerenciamento de projetos, sendo considerado um elemento essencial para o controle do mesmo. O aumento da competição em escala global e o rápido desenvolvimento tecnológico tem feito com que empresas melhorem os controles internos dos seus projetos e dos projetos dos seus clientes (Kim;Wells;Duffey,2003).Os indicadores são instrumentos de gestão essenciais nas atividades de monitoramento e avaliação dos projetos, pois permitem acompanhar o alcance das metas, identificar avanços e melhorias de qualidade. Monitorar o projeto é comparar a situação atual com a planejada, determinando se o custo e o prazo estão dentro do planejamento, tomando as medidas corretivas quando necessário (De Marco;Timur,2013).Os índices de desempenho em projetos na área de engenharia têm especial importância, pois permitem antever problemas que possam estar ocorrendo durante o andamento do projeto, possibilitando que ajustes e correções possam ser feitas, evitando desvios do planejamento. $\mathrm{O}$ método de gerenciamento por valor agregado é uma ferramenta poderosa para gerenciar o escopo, prazo e custo, permitindo obter o índice de desempenho do cronograma e do custo (Anbari, 2003).

Pesquisa realizada pelo ICPMA (International Council for Project 
Management Advancement) em 2002 demonstra que o indicador de valor agregado é o índice de desempenho mais utilizado na área de construção civil. Na tabela 1 pode ser verificado o percentual de utilização do indicador em cada seguimento da indústria. Identificou-se o percentual de $80 \%$ de utilização em projetos de construção civil, $76,47 \%$ nos demais ramos da engenharia e $56,47 \%$ na área de T.I (tecnologia da informação).A construção é um tipo de projeto complexo e com muitas incertezas, entretanto, apesar dos diferentes controles de custo a indústria da construção adotou o indicador de valor agregado para o controle de custos (Jibouri, 2003).

Tabela 1 - Percentual de aplicação do EVM por tipo de projeto

\begin{tabular}{l|r}
\hline \multicolumn{1}{c|}{ Tipo de Projeto } & $\begin{array}{c}\text { Percentual } \\
\text { das respostas }\end{array}$ \\
\hline Construção Civil & $80.00 \%$ \\
\hline Engenharia & $76.47 \%$ \\
\hline T.I. & $56.47 \%$ \\
\hline Defesa & $51.76 \%$ \\
\hline Finanças & $32.94 \%$ \\
\hline Processos & $31.76 \%$ \\
\hline Recursos Humanos & $17.65 \%$ \\
\hline Outros & $8.24 \%$ \\
\hline
\end{tabular}

Fonte: ICPMA (2002)

Mesmo sendo bem conhecida pelo mercado, a aplicação do indicador de valor agregado em projetos não é muito simples. Dependendo da forma como o indicador é utilizado, poderão ocorrer variações de desempenho no projeto que poderão esconder a real situação do mesmo. É necessário, portanto, que sejam realizados processos para a obtenção do indicador EVM de maneira adequada. É importante considerar a escolha de uma metodologia adequada para monitorar o desempenho por valor agregado (Fleming;Koppelman, 2010). Segundo Kim,Wells e Duffey (2003), o maior índice de problemas relativo ao EVM se refere ao entendimento da metodologia.Para a utilização do EVM é necessário que a empresa tenha como premissa um sistema de informação disponível e que tenha políticas e procedimentos, sendo necessário ainda treinamento adequado para a equipe de projeto (PMI Standard EVM $2^{\circ}$ ed.,2011).Segundo Kim,Wells e Duffey (2003),a utilização de um software integrado de gestão de projetos é um fator crítico de sucesso para a implementação do EVM.

A indústria da construção está ficando para trás na prática do EVM quando comparado a outras indústrias e tem dificuldades em adequar a metodologia a prática de gerenciamento de projetos (De Marco;Timur,2013).Segundo Fleming e Koppelman (2010), o mais preocupante é que muitas empresas de construção utilizam o valor planejado de custos e o valor atual de custos, não considerando a terceira dimensão que é o valor agregado. $\mathrm{O}$ indicador de valor agregado é conhecido na indústria da construção como agregado em horas ou agregado em dólares (Song,2010).

Neste trabalho iremos procurar identificar se existem diferenças entre a teoria e a prática de utilização do indicador de valor agregado na indústria da construção civil no Brasil.Inicialmente iremos formular a situação-problema, posteriormente construir premissas, revisar a literatura sobre o assunto e através de pesquisa de campo procurar identificar as diferenças mencionadas na literatura.

Esta pesquisa procura responder a seguinte questão:

Existem diferenças entre o modelo teórico e as práticas de utilização do indicador de desempenho de valor agregado na construção civil pública no Brasil?

O problema principal da pesquisa pode ser desdobrado nos seguintes itens: i) $\mathrm{O}$ indicador de valor agregado é relevante para as empresas de construção civil; ii) $\mathrm{O}$ indicador de valor agregado é aderente às necessidades das empresas de construção 
civil; iii) As empresas possuem maturidade em gestão de projetos; iv) As empresas possuem capacitação adequada para utilização do modelo de valor agregado. De acordo com Leedy (2000), após a definição do problema, o passo seguinte é a formulação das premissas que poderiam responder o problema proposto e orientar os passos seguintes da pesquisa. Para responder a questão central são formuladas as seguintes premissas:

Premissa 1 (Relevância): Há uma percepção da empresa da importância da utilização do indicador de valor agregado para o desempenho do projeto.

Premissa 2 (Adequação):Os modelos analíticos propostos de valor agregado são adequados às necessidades das empresas : (P2.1) Falta de aderência; (P2.2) Complexidade; (P2.3) Dificuldade de operacionalização.

Entende-se por falta de aderência a possibilidade dos modelos analíticos propostos de valor agregado ser adequados às necessidades das empresas de construção civil para a medição de desempenho. $\mathrm{O}$ segundo ponto, sobre a complexidade dos modelos, consiste em afirmar que os modelos de valor agregado são complexos e de difícil compreensão. Por fim, a dificuldade de operacionalização diz respeito à efetiva implantação dos modelos nas empresas, que implica também na necessidade de desenvolvimento ou aquisição de softwares, resultando em um efetivo sistema de planejamento e gestão de projetos.

Premissa 3 (Capacitação):As empresas não possuem pessoal capacitado para a implantação de modelos de indicador de desempenho de valor agregado.

Premissa 4 (Maturidade): As empresas não dispõem de maturidade em gestão de projetos.

\section{Método de Pesquisa}

A pesquisa realizada caracterizou-se como aplicada ou tecnológica, pois gera produtos e processos para aplicação imediata e prática para o assunto de indicadores de desempenho para projetos e obras de engenharia. A abordagem é exploratória, pois procura esclarecer fatos visando maior familiaridade com o problema. A escolha das obras obedeceu ao critério de relevância do valor econômico envolvido e a relevância social da obra.A validação dos resultados foi feita através de pesquisa de campo, onde foram utilizados recursos de observação em campo, analise de documentos e entrevistas informais com 03 engenheiros e 5 técnicos da área de planejamento das empresas. $\mathrm{O}$ questionário aplicado está em apêndice neste artigo. A entrevista foi face a face e o critério de escolha dos entrevistados foi o de que exercem atividades de gestão de projetos nas obras públicas selecionadas na pesquisa.A pesquisa de campo foi realizada em três obras de construção civil que ocorreram entre 2011 à 2013, no estado do Rio de Janeiro.A amostra foi escolhida por conveniência e definida por critérios de custo e de relevância social. Um projeto de obra pública refere-se a reforma de terminal aeroportuário, outro é uma estrada de acesso a um complexo industrial e o terceiro referente a um prédio administrativo de indústria farmacêutica pública. A escolha das obras que são executadas na cidade do Rio de Janeiro é justificada pela concentração de obras públicas que no momento se desenvolvem tanto do ponto de vista de eventos mundiais em vias de realização na cidade, como constituem-se em projetos integrados em programas de desenvolvimento nacional.

\section{Indicador de Valor Agregado}

$\mathrm{Na}$ literatura observa-se uma ênfase de maneira geral de indicadores nas áreas de prazo, custo, escopo e qualidade como sendo críticas para o sucesso do projeto (Pinto; Sleven, 1988).

O EVM surgiu há mais de 100 anos nos Estados Unidos, com o propósito de confrontar o trabalho realizado e o custo. Entretanto, foi partir da década de 60 que o EVM ganhou sua primeira publicação formal conduzida por uma experiência bem sucedida em um projeto da força aérea norteamericana. Da década de 60 a 90 o EVM se tornou o padrão de projetos do governo dos Estados Unidos. 
Na década de 90, foi publicado o padrão sob o código ANSI/EIA-748-1998 padronizando a utilização do valor agregado. Esta publicação, por trazer simplificações na terminologia e critérios de aplicação, foi bem recebida pela iniciativa privada que desde então tem adotado e reconhecido os benefícios de sua utilização (FLEMING; KOPPELMAN, 2010). O uso do indicador se intensificou no ano de 1993 como uma variação do C/SCSC (Cost Schedule Control System) na utilização no DoC (Department of Commerce) Departamento de comércio. Em 1994 o FBI começa a utilizar este indicador, em 1996 foi inserido no PMBOK tendo a sua utilização ainda mais difundida em empresas e instituições em todo o mundo.

$\mathrm{O}$ indicador de valor agregado avalia o desempenho do projeto em 03 dimensões fundamentais: prazo, escopo e custo. Estas 03 dimensões são reconhecidas pelo PMI como o "triangulo de ferro" e é de reconhecida importância o seu controle para a eficiência em projetos (PMBOK, 2013). O indicador de valor agregado é obtido a partir do custo de cada etapa do projeto. Para a obtenção dos indicadores de valor agregado é necessário que as atividades sejam quantificadas em custo e que as datas de conclusão de cada tarefa sejam determinadas. Segundo (Vargas, 2008) a técnica de valor agregado atende ao objetivo de interligar o custo o prazo e o escopo.

A Técnica de valor agregado é considera uma das mais poderosas ferramentas de controle de projetos disponível no mercado e tem foco na relação entre os custos reais e o trabalho realizado no projeto dentro de um período determinado de tempo(Vargas, 2008).

O indicador de valor agregado é também conhecido como Earned Value Management (EVM), outra nomenclatura usada é Análise de Valor Agregado (AVA), alguns autores ainda denominam como indicador de curva "S" devido à forma que é representado graficamente. Neste trabalho iremos utilizar a nomenclatura de EVM ou valor agregado.

$\mathrm{O}$ indicador de valor agregado é obtido a partir das atividades concluídas e o seu valor associado, chamado de valor agregado. Os valores acumulados mensalmente irão gerar a curva de valor agregado. No gráfico 1 pode ser verificado a linha base do orçamento chamado de COTA ( Custo orçado do trabalho agendado), o COTR (Custo orçado para o trabalho realizado) e o CRTR (Custo real do trabalho realizado).

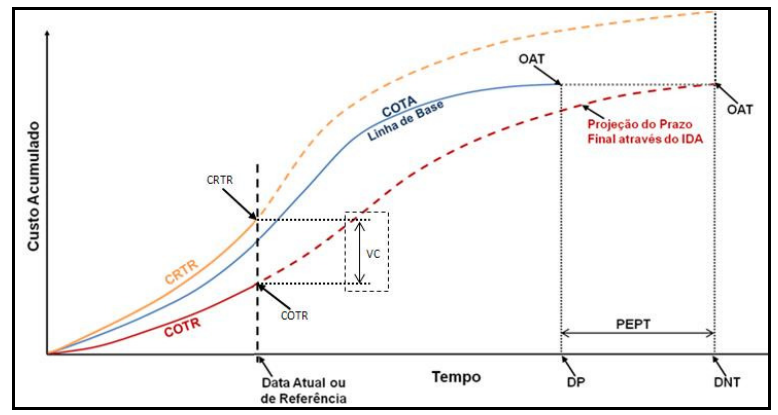

Gráfico 1 - Gráfico de valor agregado Fonte: Adaptado pelo autor do PMI Standard EVM $2^{\circ}$ ed. (2011)

O padrão ANSI/EAI 748 define 32 processos para a obtenção do EVM, estes processos foram posteriormente simplificados pelo PMBOK em 1996. Segundo Fleming e Koppelman (2010), esta simplificação trouxe grande aceitação ao uso do indicador e podem ser plenamente utilizados em projetos de qualquer tamanho. Na figura 1 são detalhados os principais processos do ciclo de planejamento e operação do EVM.

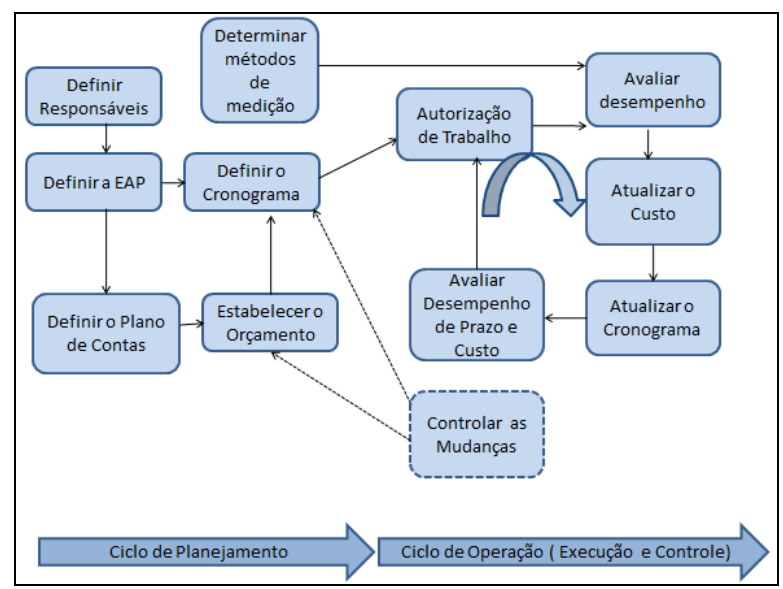

Fig. 1 - Processos do indicador de valor agregado ( EVM )

Fonte: Adaptado de PMI Standard EVM $2^{\circ}$ ed. (2011) e Kezner (2010) . 
Segundo o PMBOK(2013), ao executar as tarefas do projeto é importante dividir o trabalho em partes menores, de modo que seja fácil a definição e o controle. As partes menores da divisão do escopo são conhecidas como EAP (Estrutura analítica do projeto) e para estabelecer a EAP é necessário que todos os processos anteriores do gerenciamento de projetos já estejam concluídos como: termo de abertura do projeto,estratégia de gerenciamento das partes interessadas, documentos de requisitos e definição do escopo.

Segundo FLEMING e KOPPELMAN (2010), o plano de contas é utilizado para o controle financeiro do projeto e deverá integrar a EAP com o trabalho que deverá ser realizado permitindo que as medições de custo possam ser contabilizadas para cada item de EAP. Na figura $1 \mathrm{o}$ processo de definir o plano de contas utiliza a divisão dos pacotes de trabalho anteriormente definidas pela EAP. Cada pacote de trabalho terá um código de conta já definido pela EAP e servirá de base para que as despesas sejam analisadas.

$\mathrm{O}$ processo da figura 1 de estabelecer o orçamento consiste em dividir o custo de cada item da EAP, que deverá totalizar o custo do projeto. O orçamento deverá incluir os itens de custo direto, custo indireto, recursos materiais e humanos para cada atividade e ainda os fundos de reserva. Este custo será alocado em contas de plano de custo já definidas anteriormente.

$O$ processo de definir o cronograma na figura 1 consiste em definir a linha base do cronograma, estabelecendo as datas iniciais e finais de cada etapa do projeto. Este cronograma deverá ter o custo de cada pacote de trabalho incluído. O cronograma final integra os custo e prazos do projeto e será utilizado para medir a linha base de desempenho conhecido como PMB (Performance Measurement Baseline)(PMI Standard EVM $2^{\circ}$ ed. , 2011).

No processo figura 1 de determinar os métodos de medição deve ser definido claramente como cada item será quantificado. A medição irá depender do tipo de contrato que foi estabelecido e também do tipo de atividade que será realizada. Os tipos de atividade são definidas como: esforço discreto, esforço repartido e o nível de esforço. $\mathrm{O}$ esforço discreto tem a seguinte subdivisão: fórmula fixa, peso em marcos, porcentagem concluída e medida física ( $P M I$ Standard EVM $2^{\circ}$ ed., 2011).

Após a conclusão dos processos de planejamento, iniciam-se o ciclo de operação. Para controlar a execução é necessário avaliar a variação de desempenho, considerando o que foi realizado dentro do prazo estipulado. A variação do desempenho do projeto é obtida através da comparação do valor previsto (linha base do projeto) com o valor realizado PMBOK (2013). Ao iniciar o ciclo de operação, deve ser emitido o documento de autorização de trabalho (Kezner,2010).

A partir do processo de avaliação de desempenho é realizado o processo de atualizar o cronograma e atualização do custo. A atualização do custo do projeto é obtida a partir do custo de materiais e serviços durante o período de avaliação. Cada item de custo é definido em um plano de contas previamente estabelecido.

No processo de avaliar o desempenho de custo e prazo será obtido o indicador de desempenho de custo, IDC (índice de desempenho de custo) e o indicador de desempenho de prazo, IDP (índice de desempenho de prazo).

$\mathrm{O}$ processo de controlar as mudanças deverá prever os controles de mudança do projeto e prever ainda medidas corretivas para o caso de desvios nos índices de prazo e custo (PMI Standard EVM $2^{\circ}$ ed., 2011).

\section{Maturidade em gestão de projetos.}

$\mathrm{Na}$ análise da execução dos processos de EVM, foi necessário identificar também a maturidade em gestão de projetos das empresas dos projetos selecionados. A maturidade em gestão de projetos segundo o PMBOK (2013) é baseado no modelo OPM3 (Organizational Project Management Maturity Model). Os níveis definidos pela OPM3 são:

-Nível 1 - As práticas de gerenciamento de projetos na organização são praticamente inexistentes. Não há interesse no sentido de reconhecer quais são os benefícios advindos da utilização das práticas de gerenciamento de 
projetos. Quando existe algum reconhecimento, é meramente para atender requisitos determinados por algum cliente na contratação dos serviços da organização.

-Nível 2 -São percebidas as necessidades de implementar processos e metodologias que suportem o gerenciamento de projetos. Reconhece-se a importância de se adquirir conhecimentos em gerenciamento de projetos. $\mathrm{O}$ gerenciamento de projetos é feito para o escopo, tempo e custo.

-Nível 3 - Os processos estão integrados e existe apoio da alta gerência. São utilizadas metodologias de gerenciamento de projetos baseadas em guias e lista de verificação. O treinamento em gerenciamento de projetos é contínuo. O gerenciamento de projetos faz parte da cultura da empresa e seus benefícios são reconhecidos.

-Nível 4 - É estabelecido um escritório de gerenciamento de projetos e este é dedicado ao aprimoramento contínuo dos processos e da documentação de projeto.São feitas aferições (benchmarking) que abrangem os aspectos quantitativos e qualitativos dos projetos.

-Nível 5 - Repetição do processo de gerenciamento de projeto de maneira otimizada, as melhorias contínuas e lições aprendidas são documentadas. Existe planejamento estratégico contínuo para o gerenciamento de projetos.

Segundo a pesquisa de maturidade em gestão de projetos realizada por Darci Padro (Prado, 2012), a maturidade média das empresas de construção civil em obras públicas é baixa tendo o valor de 2,61 de acordo com a avaliação realizada no ano de 2012.

\section{Pesquisa de Campo}

Com o objetivo de avaliar a prática da indústria da construção civil na utilização de desempenhos de projeto utilizando a análise de valor agregado, foram analisados 3 projetos de construção civil.

Os projetos são obras realizadas no Rio de Janeiro no período de 2011, 2012 e 2013. As empresas são de grande porte de diferentes áreas de atuação (Energia, Aeroportuária e Saúde), todas com atuação nacional. Uma breve descrição de cada projeto se encontra descrita no quadro 1.

\begin{tabular}{|c|c|c|c|}
\hline $\begin{array}{c}\text { Item do } \\
\text { projeto }\end{array}$ & Projeto 1 & Projeto 2 & Projeto 3 \\
\hline Escopo & $\begin{array}{l}\text { Estrada de } \\
\text { Acesso de } \\
\text { acesso de } \\
\text { equipamentos } \\
\text { para complexo } \\
\text { industrial. }\end{array}$ & $\begin{array}{l}\text { Ampliação de } \\
\text { pista } \\
\text { aeroportuária. }\end{array}$ & $\begin{array}{l}\text { Prédio } \\
\text { comercial } \\
\text { administrativo } \\
\text { de } 04 \text { andares } \\
\text { para indústria } \\
\text { farmacêutica } \\
\text { pública. }\end{array}$ \\
\hline Início & $10 / 01 / 2012$ & $29 / 10 / 2011$ & $02 / 04 / 2012$ \\
\hline Prazo & 24 meses & 24 meses & 23 meses \\
\hline Orçamento & $\begin{array}{c}\mathrm{R} \$ \\
190.000 .000,00\end{array}$ & $\begin{array}{c}\mathrm{R} \$ \\
64.000 .000,00\end{array}$ & $\begin{array}{c}\mathrm{R} \$ \\
44.780 .000,00\end{array}$ \\
\hline $\begin{array}{l}\text { Área de } \\
\text { atuação }\end{array}$ & Energia & $\begin{array}{l}\text { Infraestrutura } \\
\text { Aeroportuária }\end{array}$ & Saúde Pública \\
\hline $\begin{array}{l}\text { Tipo de } \\
\text { empresa }\end{array}$ & Pública- S/A & Pública- S/A & $\begin{array}{l}\text { Pública- } \\
\text { Fundação }\end{array}$ \\
\hline $\begin{array}{l}\text { Porte da } \\
\text { empresa }\end{array}$ & Grande & Grande & Grande \\
\hline $\begin{array}{c}\text { Ramo da } \\
\text { empreiteira }\end{array}$ & $\begin{array}{c}\text { Construção } \\
\text { pesada }\end{array}$ & $\begin{array}{l}\text { Construção } \\
\text { pesada }\end{array}$ & $\begin{array}{c}\text { Construção } \\
\text { Civil }\end{array}$ \\
\hline $\begin{array}{l}\text { Tipo de } \\
\text { contrato }\end{array}$ & Preço Global & Preço Global & Preço Global \\
\hline $\begin{array}{l}\text { Software } \\
\text { utilizado }\end{array}$ & $\begin{array}{l}\text { MsExcell, } \\
\text { MsProject }\end{array}$ & $\begin{array}{l}\text { MsExcell, } \\
\text { MsProject }\end{array}$ & $\begin{array}{l}\text { MsExcell, } \\
\text { MsProject }\end{array}$ \\
\hline \multicolumn{4}{|c|}{$1-$ Dados } \\
\hline
\end{tabular}

Os projetos selecionados foram analisados através de pesquisa no campo e os resultados foram resumidos no quadro 2 e 3 . No quadro 2 foi feita uma comparação entre o que foi realizado na prática em cada projeto e a teoria apresentada sobre o EVM. Os itens foram separados de maneira que o item 1 se refere as fórmulas e gráficos de valor agregado, os itens de 2 à 13 se referem aos processos de obtenção do EVM .Os requisitos de 1 à 6 são requisitos do ciclo de planejamento e os itens de 7 à 13 são requisitos do ciclo de operação. 


\begin{tabular}{|c|c|c|c|c|}
\hline Item & $\begin{array}{c}\text { formações sobre } \\
\text { o processos do } \\
\text { EVM }\end{array}$ & Proj. 1 & Proj. 2 & Proj.3 \\
\hline 1 & $\begin{array}{l}\text { As fórmulas de } \\
\text { cálculo dos } \\
\text { índices de } \\
\text { desempenho e } \\
\text { gráficos foram } \\
\text { realizadas de } \\
\text { acordo com a } \\
\text { teoria }\end{array}$ & Sim & Sim & Não \\
\hline 2 & $\begin{array}{l}\text { Definir a EAP e } \\
\text { responsáveis }\end{array}$ & Sim & Sim & Não \\
\hline 3 & $\begin{array}{l}\text { Definir o plano } \\
\text { de contas }\end{array}$ & Não & Não & Não \\
\hline 4 & $\begin{array}{l}\text { Estabelecer o } \\
\text { orçamento }\end{array}$ & Sim & Sim & Sim \\
\hline 5 & $\begin{array}{l}\text { Determinar } \\
\text { métodos de } \\
\text { medição }\end{array}$ & Sim & Sim & Não \\
\hline 6 & $\begin{array}{l}\text { Definir o } \\
\text { cronograma }\end{array}$ & Sim & Sim & Sim \\
\hline 7 & $\begin{array}{l}\text { Atualizar o } \\
\text { cronograma }\end{array}$ & Sim & Não & Não \\
\hline 8 & $\begin{array}{l}\text { Atualizar o } \\
\text { custo }\end{array}$ & Não & Não & Não \\
\hline 9 & $\begin{array}{l}\text { Avaliar } \\
\text { desempenho de } \\
\text { prazo }\end{array}$ & Sim & Sim & Não \\
\hline 10 & $\begin{array}{l}\text { Avaliar } \\
\text { desempenho de } \\
\text { custo }\end{array}$ & Não & Não & Não \\
\hline 11 & $\begin{array}{l}\text { Controlar as } \\
\text { mudanças }\end{array}$ & Sim & Não & Não \\
\hline 12 & $\begin{array}{l}\text { Autorização do } \\
\text { trabalho }\end{array}$ & Sim & Não & Não \\
\hline 13 & $\begin{array}{l}\text { Avaliar o } \\
\text { desempenho }\end{array}$ & Sim & Não & Não \\
\hline
\end{tabular}

Quadro 2 - Análise comparativa da metodologia do valor agregado

No quadro 3 foi resumido os dados das entrevistas realizadas durante a execução do projeto. As entrevistas seguiram o roteiro em apêndice e tiveram por objetivo verificar as premissas levantadas de: relevância, aderência, complexidade, dificuldade de operacionalização, capacitação em valor agregado e maturidade em projetos.

\begin{tabular}{|c|c|l|c|c|c|}
\hline $\begin{array}{l}\text { Ite } \\
\mathrm{m}\end{array}$ & $\mathrm{Nr}$ & Premissa & $\begin{array}{c}\text { Proj. } \\
1\end{array}$ & $\begin{array}{c}\text { Proj. } \\
1\end{array}$ & $\begin{array}{c}\text { Proj. } \\
1\end{array}$ \\
\hline 1 & $\mathrm{P1}$ & $\begin{array}{l}\text { A } \\
\text { empresa } \\
\text { considera } \\
\text { o uso do } \\
\text { valor } \\
\text { agregado } \\
\text { como } \\
\text { relevante. }\end{array}$ & Sim & Sim & Sim \\
\hline
\end{tabular}

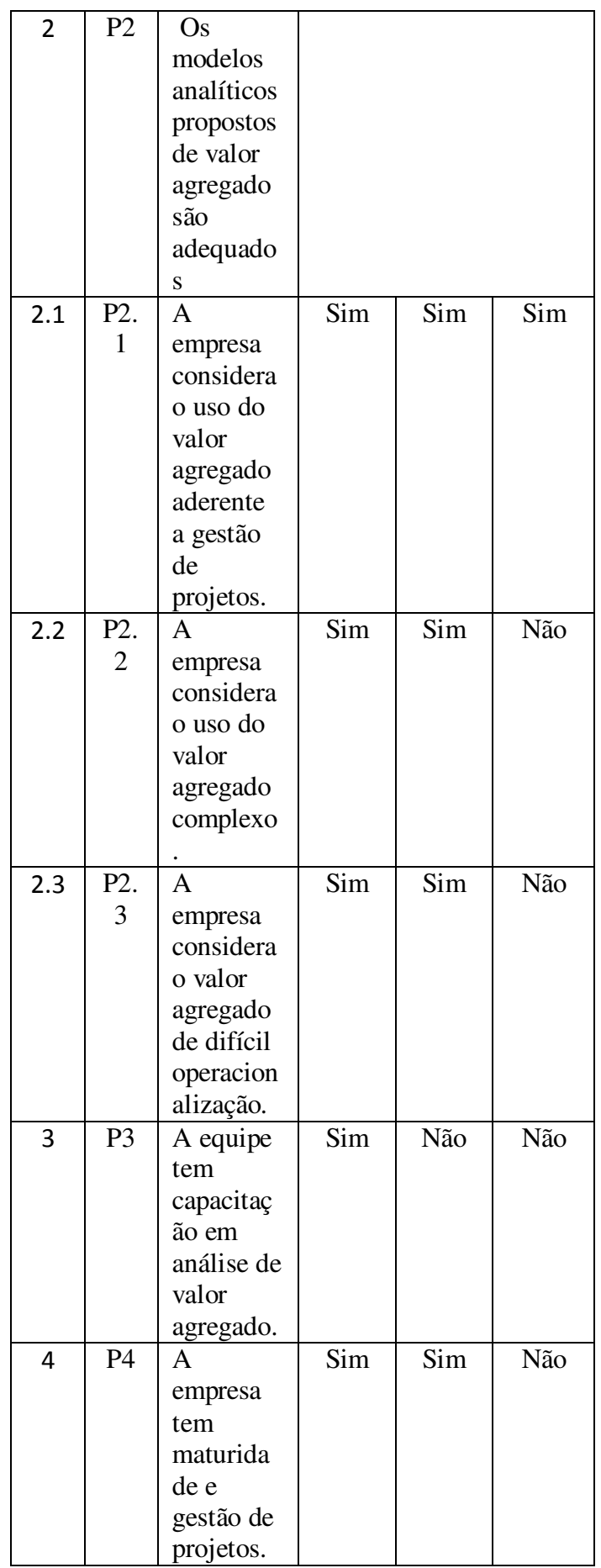

Quadros 3 - Dados das empresas analisadas em relação às premissas levantadas

\section{Análise de Resultados}

A partir da revisão bibliográfica e dos resultados da pesquisa de campo, pretende-se encontrar diferenças entre a teoria e a prática da análise de valor agregado na construção civil. A análise do problema foi feita a partir das premissas formuladas. 
$\mathrm{Na}$ avaliação dos resultados do quadro 2 , pode-se observar uma melhor utilização da teoria de EVM em ordem crescente do projeto 1 ao projeto 3 . Pode-se observar ainda que o atendimento a teoria de EVM na fase de planejamento é maior que na fase de execução e controle. Isto demonstra que as empresas apresentam maior dificuldade na fase de execução e controle nos processos de valor agregado.

Observa-se na análise comparativa dos projetos no quadro 2 que a metodologia de valor agregado é melhor utilizada no projeto 1 e pior utilizada no projeto 3 .

Com o objetivo de melhor compreender as empresas de cada projeto analisado e validar as premissas formuladas, foi analisado as informações de cada empresa no quadro 3. Os dados do quadro 3 foram obtidos através de entrevista que se encontra em apêndice.

$\mathrm{O}$ item $1(\mathrm{P} 1)$ referente a relevância do valor agregado, foi considerado relevante por todos os projetos a análise de valor agregado.

$\mathrm{O}$ item 2 (P2.1) de análise relativa a aderência do valor agregado todos os projetos consideraram o valor agregado aderente, ou seja a possibilidade dos modelos analíticos propostos de valor agregado serem adequados as necessidades das empresas de construção civil para a medição de desempenho.

$\mathrm{O}$ item 3 (P2.2) referente a competência do valor agregado, foi observado maior competência no projeto 1 e menor competência no projeto 3 .

$\mathrm{O}$ item 4 (P2.3) referente a dificuldade de operacionalização do EVM , foi verificado que os projetos 1 e 2 consideraram que é difícil operacionalização, enquanto o projeto 3 considerou de fácil operacionalização.

$\mathrm{O}$ item $5(\mathrm{P} 3)$ referente a capacitação da equipe foi verificado que as empresas do projeto 1 tinha capacitação específica em valor agregado.

$\mathrm{O}$ item $6(\mathrm{P} 4)$ referente a maturidade em gestão de projetos foi verificado que as empresas tinham maturidade de projeto crescente do projeto 1 ao projeto 3 .

\section{Conclusão e Sugestão de Novas \\ Pesquisas}

Utilizando-se de pesquisa qualitativa, incluindo observação em campo, entrevistas e analise de documentos das empresas e das obras estudadas, podem ser elaboradas as respostas à questão de pesquisa e avaliadas as premissas formuladas.

A questão de pesquisa proposta:Existem diferenças entre o modelo teórico e as práticas de utilização do indicador de desempenho de valor agregado em gestão de projetos de obras públicas?

Foram verificadas evidencias que existem diferenças entre a teoria e a prática da análise do valor agregado.

Foi constatado nesta pesquisa que a diferença entre a teoria e a prática na análise de valor agregado decorre principalmente pela falta de maturidade em gestão de projetos e capacitação nas empresas pesquisadas.

Premissa 1 - Relevância

Analisando os resultados encontrados no item 1 do quadro 3 referente a relevância, foi confirmado nas três empresas pesquisadas que existe uma percepção da empresa da relevância na utilização da análise de valor agregado para o desempenho do projeto.

Foi verificado na pesquisa de campo que as empresas consideram relevante a análise do valor agregado especialmente pelo fato de dar uma visão gráfica do desempenho do projeto. Foi constatado ainda que apesar de não utilizarem adequadamente o EVM houve um ganho em relação ao seu uso, pois além da visualização gráfica pode-se antecipar problemas no projeto através dos índices de desempenho de custo e prazo. Foi verificado ainda que ao controlar o projeto utilizando o EVM as empresas procuram controlar os itens principais do indicador que é o escopo, custo e prazo.

Premissa 2 - Adequação

Analisando os resultados encontrados no quadro 3, foi observado que as empresas 
consideram o EVM aderente as suas necessidades pois permitem realizar o controle de custo associado ao escopo do projeto e ao cronograma do projeto. Entretanto consideram a metodologia complexa e de difícil operacionalização.

Premissa 3 - Capacitação

Foi verificado através das informações do quadro 3 que as empresas com maior capacitação foram as que conseguiram atender melhor os requisitos analisados para o EVM.

Premissa 4 - Maturidade em gestão de projetos

Foi observado através das informações dos quadros 2 e 3 que as empresas com maior maturidade em gestão de projetos foram as que conseguiram atender melhor os requisitos analisados para o EVM.

Embora a pesquisa tenha sido realizada com um número limitado de projetos de obras públicas,a amostra definida por conveniência possui relevância devido ao benefício social e aos custos envolvidos.

Constata-se uma correlação entre a maturidade na gestão de projetos e capacitação com a correta aplicação dos

\section{Referências}

\section{Al-JIBOURI,SAAD. Monitoring system and their effectiveness for project control} in construction. International Journal of project Management, 2003. 21, 145-154

ANBARI, Frank T. .Earned Value Project Management: Method and Extension, Project Management Journal,2003. 34,12-23.

CRAWFORD L.; ENGLAND, D.; POLLACK, J.Uncovering the trends in Project management: Journal emphases over the last 10 years. International Journal of Project Management (IJPM),2005, v. 24, p. 175-184.

DE MARCO, Alberto; NarbaevTimur, Earned Value-Based performance conceitos de EVM, pois as empresas com maior maturidade em projeto e capacitação foram as que utilizaram mais adequadamente o EVM.

Podemos inferir, portanto que a maturidade em gestão de projetos e a capacitação da equipe é de fundamental importância para que o uso do valor agregado. A capacitação em valor agregado inclui o conhecimento em gestão de projetos, custeio de obras e a teoria de valor agregado.

Foi constatado que a maior dificuldade das empresas está na no ciclo de operação do projeto, onde é necessária a obtenção da curva de valor agregado e a curva de custo.Foi observado ainda que a utilização de um software que possa integrar a análise de valor agregado é um fator que poderia facilitar o uso do EVM.

A pesquisa confirma outras pesquisas realizadas por autores de diferentes países sobre o indicador de valor agregado e citado no início deste artigo e aprofunda o tema sobre o uso do indicador de valor agregado, indicando as principais dificuldades na sua implementação. Propõe-se a elaboração de novas pesquisas em outras obras, com diversas empresas com portes variados para ampliar e confirmar as conclusões obtidas nesta pesquisa.

monitoring of facility construction project, Journal of Facilities Management, 2013, V.11,N. 1

FLEMING, Quentin W.; KOPPELMAN, Joel M. Earned value: project management. 4. ed.Pennsylvania, PMI, 2010. 212 p

ICPMA, International Council for Project Management Advancement "Response to Standards Australia on: Draft Standard for Project Performance Measurement Using Earned Value V5.6". IPCMA, maio 2002

KERZNER Harold, Project Management Best Practices: Achieving Global Excellence, 1st Edition, 2006; and 2nd Edition, 2010, John Wiley \&Sons and LIL Publishers 
KIM E.H., Wells Jr. W.G., Duffey M.R.,A model for effective implementation of Earned Value Management methodology, International Journal of Project Management,2003.

LEEDY, P. D. , Practical Research: Planning and Design, $7^{\circ}$ ed., Nova Jersey : PrenticeHall,2000.

PMBOK Guide $5^{\circ}$ Ed.-PROJECT MANAGEMENT BODY OF KNOWLEDGE- Project Management Institute, 2013.

PMI Standard EVM $2^{\circ}$ ed. -PRACTICE STANDARD FOR EARNED VALUE MANAGEMENT - Project Management Institute 2 ed. , 2011.

PINTO,JK; SLEVIN, D.P. Critical factors in successful project implementation. In:

Apêndice - Questionário para entrevista na

pesquisa de campo

\begin{tabular}{|c|l|}
\hline Item & Perguntas \\
\hline 1 & Qual o nome da Empresa? \\
\hline 2 & Qual o nome do Gerente ? \\
\hline 3 & Qual o escopo ? \\
\hline 4 & Quando foi o início? \\
\hline 5 & Qual é o prazo? \\
\hline 6 & Qual o preço aproximado do projeto? \\
\hline 7 & Qual a área de atuação da empresa? \\
\hline 8 & Qual a categoria jurídica de empresa? \\
\hline 9 & Qual o porte da empresa? \\
\hline 10 & Qual o ramo da empresa? \\
\hline 11 & $\begin{array}{l}\text { Qual o tipo de contrato com a } \\
\text { construtora? }\end{array}$ \\
\hline
\end{tabular}

FINCH,P. Applying the project implementation profile to an information systems project. Project Management Journal, v.34,n. 3; p. 32, 1987.

PRADO, Darci http://www.maturityresearch.com/novosite /index_br.html , Pesquisa de Maturidade de Gestão de Projetos, 2012

SONG, LINGGUANG. Earned Value Management: A Global and CrossIndustry Perspective on Current EVM Practice,2010.PMI- Project Management Institute.

VARGAS, RICARDO. Análise de valor agregado em projetos. 3 ed. Rio de Janeiro: Brasport,2008.

\begin{tabular}{|c|l|}
\hline 12 & $\begin{array}{l}\text { Qual o software utilizado para o } \\
\text { EVM? }\end{array}$ \\
\hline 13 & $\begin{array}{l}\text { A empresa considera o uso do valor } \\
\text { agregado como relevante? }\end{array}$ \\
\hline 14 & $\begin{array}{l}\text { A empresa considera o uso do valor } \\
\text { agregado aderente? }\end{array}$ \\
\hline 15 & $\begin{array}{l}\text { A empresa considera o uso do valor } \\
\text { agregado complexo? }\end{array}$ \\
\hline 16 & $\begin{array}{l}\text { A empresa considera o EVM de } \\
\text { difícil operacionalização? }\end{array}$ \\
\hline 17 & $\begin{array}{l}\text { A equipe apresenta capacitação em } \\
\text { análise de valor agregado? }\end{array}$ \\
\hline 18 & $\begin{array}{l}\text { Avaliando a empresa de acordo com o } \\
\text { grau de maturidade em gestão de } \\
\text { projetos do PMBOK.Qual seria a } \\
\text { classificação da sua empresa quanto a } \\
\text { maturidade em gestão de projetos no } \\
\text { nível 1 a 5 do OPM3? }\end{array}$ \\
\hline
\end{tabular}

